\title{
静荷重を受けたモノリシックセラミックスの残存強度特性*
}

\author{
松田 伸也 ${ }^{* 1}$ ，黄木 景二 ${ }^{* 2}$
}

\section{Residual Strength Properties of Monolithic Ceramics after Static Loading}

\author{
Shinya MATSUDA*1 and Keiji OGI \\ ${ }^{* 1}$ Numazu National College of Technology, Department of Mechanical Engineering, \\ Ooka 3600, Numazu-shi, Shizuoka, 410-8501 Japan
}

This paper presents residual strength properties of monolithic ceramics after static loading. First, a residual strength prediction model is proposed on the basis of the slow crack growth (SCG) concept. Second, the residual strengths in soda glass and alumina ceramics $\left(\mathrm{Al}_{2} \mathrm{O}_{3}\right)$ after static loading were measured. The fracture surfaces were then observed. Third, the experimental results were compared with the predictions using the model. As a result, the experimental data for soda glass was in good agreement with the prediction. In contrast, the agreement was worse for $\mathrm{Al}_{2} \mathrm{O}_{3}$. $\mathrm{The}$ residual strength in $\mathrm{Al}_{2} \mathrm{O}_{3}$ was larger than the fracture strength and increased with increasing loading time.

Key Words : Monolithic Ceramics, Residual Strength, Static Loading, Slow Crack Growth

\section{1. 緒言}

近年, 省資源・省エネルギー・リサイクルをキーワードとして, 地球環境に優しく, 高性能・高機能の機械・電気部品の 開発が要求されている. その中で, モノシックセラミックス(以下, セラミックス) は, 高比強度, 耐摩耗性, 耐熱性など優 れた特性を有しているため, 国内で注目を浴びている. 例えば, 窒化厅イ素 $\left(\mathrm{Si}_{3} \mathrm{~N}_{4}\right)$ は, 軸受球としての市場が大幅に拡 大しており, 品質評価のために Indentation-Fracture (IF) 法を国際化する試みが行われている(1).アルミナ $\left(\mathrm{Al}_{2} \mathrm{O}_{3}\right)$ は, 生 体との親和性が良いことから医療用インプラントとして適用されている. 炭化ケイ素 $(\mathrm{SiC})$ は, 高熱伝導率を有し, 化学的 安定性に優れているため, 航空宇宙分野におけるミラーデバイスへの適用が期待されている. 特に, 高強度反応焼結 $\mathrm{SiC}$ と呼ばれる新しい材料が開発され, その適用が試みられている(2). さらに, ジルコニア $\left(\mathrm{ZrO}_{2}\right)$ を用いた固体酸化物型 燃料電池 (SOFC)の市場も大きく成長している.このように様々な分野でセラミックスの市場が大幅に拡大しており，長期 信頼性確保が要求されている. そのためには, 損傷や破壊に関する基礎的かつ統合的な研究が必要不可欠である.

1970 年代のオイルショックを契機にして, 諸国においてセラミックス製自動車エンジンを開発する国家プロジェクトが始 まった. その結果, セラミックスの強度や寿命評価の研究は盛んに行われてきた. Evans $ら^{(3) \sim(4)}$ は損傷過程を解明するこ とで SCG (Slow Crack Growth) 理論を構築し, 損傷予測のための基礎的解析手法や保証試験後の残存強度解析手法を 確立した. その後, 多くの研究者が種々のセラミックスを用いて, SCG 理論に基づき S-N 線図や S-t 線図の予測, SCG パラメータ評価を行ってきた ${ }^{(5)}$.さらに 1990 年代には, ガスタービンブレードなど高信頼性が要求される構造物に適用す るために, SCG 理論とワイブル分布を組合せた信頼性解析手法が開発された ${ }^{(6)}$. 他方で, 野島 ${ }^{(7)}$ 保証試験後の残存 強度解析手法について言及している. しかしながらその後, 強度や寿命信頼性に関する研究は衰退し, 近年はセラミック スの信頼性自体を底上げするためプロセス研究が主流となっている. したがって, 長期使用中の残存強度に関する研究 は著者の知る限り存在しない.

そこで本研究では，長期使用中の残存強度特性を明らかにすることを目的とし，静荷重を受けたセラミックスの 残存強度特性について検討した。初めに, SCG 理論に基づき残存強度予測モデルを構築した。次に，静荷重を受

* 原稿受付 2012 年 12 月 13 日

*1 正員，沼津工業高等専門学校機械工学科（广410-8501＼cjkstart静岡県沼津市大岡 3600）

*2 正員, 愛媛大学大学院理工学研究科

E-mail:matsuda@numazu-ct.ac.jp 
けたソーダガラスおよび $\mathrm{Al}_{2} \mathrm{O}_{3}$ の残存強度とモデルの予測結果を比較するとともに, 破面観察を行った.

\section{SCG 理論に基づく残存強度予測モデル}

多数のき裂を有するぜい性材料が任意の負荷応力 $\sigma(t)$ を受けたとき, 存在する長さ $a$ の初期き裂の応力拡大係 数 $K_{\mathrm{I}}$ は, $Y \sigma(t) \sqrt{a}$ と表される. ここで $Y$ はき裂の形状によって決定される形状補正係数である. SCG 則は, Evans\&Fuller ${ }^{(3)}$ にって,

$$
v=\frac{\mathrm{d} a}{\mathrm{~d} t}=C\left(\frac{K_{\mathrm{I}}}{K_{\mathrm{IC}}}\right)^{n}
$$

と表される，ここで， $n$ はき裂伝ぱ指数， $K_{\mathrm{IC}}$ は破壊じん性值， $C$ は $K_{\mathrm{I}}=K_{\mathrm{IC}}$ でのき裂進展速度である. 今, 静 的応力 $\bar{\sigma}$ が時間 $t_{\mathrm{R}}$ まで作用したとき, 長さ $a_{\mathrm{i}}$ のき裂は長さ $a_{\mathrm{R}}$ まで安定成長することを考える. このとき, 式 (1) に $K_{\mathrm{I}}=Y \sigma(t) \sqrt{a}$ を代入して積分すれば,

$$
a_{\mathrm{i}}^{-\lambda}-a_{\mathrm{R}}{ }^{-\lambda}=C \lambda \alpha^{n} \bar{\sigma}^{n} t_{\mathrm{R}}
$$

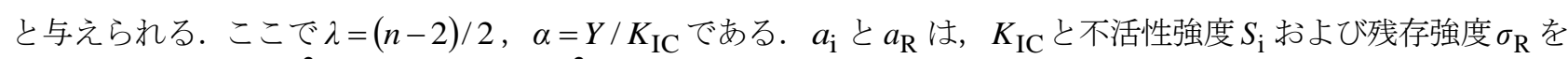
用いて $a_{\mathrm{i}}=\left(K_{\mathrm{IC}} / Y S_{\mathrm{i}}\right)^{2}, a_{\mathrm{R}}=\left(K_{\mathrm{IC}} / Y \sigma_{\mathrm{R}}\right)^{2}$ とそれぞれ表される.これら 2 式を式 (2) に代入することによって $\sigma_{\mathrm{R}}$ として,

$$
\sigma_{\mathrm{R}}=S_{\mathrm{i}}\left(1-C \lambda \alpha^{2} \frac{\bar{\sigma}^{n} t_{\mathrm{R}}}{S_{\mathrm{i}}^{2 \lambda}}\right)^{1 / 2 \lambda}
$$

が得られる. 一方，式（3）において $\sigma_{\mathrm{R}}=\bar{\sigma}$ と書き換えれば，破断時間 $t_{\mathrm{f}}$ は，

$$
t_{\mathrm{f}}=\frac{S_{\mathrm{i}}^{2 \lambda}}{C \lambda \alpha^{2}} \bar{\sigma}^{-n}\left(1-\left[\frac{\bar{\sigma}}{S_{\mathrm{i}}}\right]^{2 \lambda}\right)
$$

と書ける.いま， $S_{\mathrm{i}}$ および $\mathrm{t}_{\mathrm{f}}$ が 2 母数ワイブル分布に従うとき，破壞確率 $F$ を用いて，

$$
S_{\mathrm{i}}^{*}(F)=S_{\mathrm{o}} \sqrt[m_{\mathrm{s}}]{-\ln (1-F)}, t_{\mathrm{f}}{ }^{*}(F)=t_{\mathrm{o}} \sqrt[m_{\mathrm{f}}]{-\ln (1-F)}
$$

とそれぞれ与えられる.ここで, $m_{\mathrm{s}}, m_{\mathrm{f}}$ および $S_{\mathrm{o}}, t_{\mathrm{o}}$ はそれぞれ形状母数と尺度母数である. 式 (3) と式 (4) から $C \lambda \alpha^{2}$ を消去し， $S_{\mathrm{i}}$ と $t_{\mathrm{f}}$ を式（5）の $S_{\mathrm{i}}{ }^{*}(F)$ と $t_{\mathrm{f}}{ }^{*}(F)$ でそれぞれ置き換えることによって $\sigma_{\mathrm{R}}$ は，

$$
\sigma_{\mathrm{R}}=S_{\mathrm{i}}^{*}(F)\left(1-\left\{1-\left[\frac{\bar{\sigma}}{S_{\mathrm{i}}^{*}(F)}\right]^{2 \lambda}\right\} \frac{t_{\mathrm{R}}}{t_{\mathrm{f}}{ }^{*}(F)}\right)^{1 / 2 \lambda}
$$

として与えられ，確率論的に予測できる.ここで， $t_{\mathrm{R}}=t_{\mathrm{f}}{ }^{*}(F)$ ならば $\sigma_{\mathrm{R}}=\bar{\sigma}$ である.

\section{3. 試験片と残存強度試験}

試験片は，市販のソーダガラス $\left({ }^{(} 5 x^{t} 5 x^{L} 40 \mathrm{~mm}\right)$ および $\mathrm{Al}_{2} \mathrm{O}_{3}$ （ファインセラミックスセンター製，リファセラム） ( $\left.{ }^{w} 4 x^{t} 3 x^{L} 40 \mathrm{~mm}\right)$ を用いた. 自作したてこ式の静疲労試験機を用いて, 室温大気中・4点曲げ（下スパン $L_{1}=30 \mathrm{~mm}$ ，上スパ ン $L_{2}=10 \mathrm{~mm}$ ) で静荷重を与えた.ここで $\bar{\sigma}$ は, 表 1 に示寸 4 点曲げ強度のワイブルプロットより得たワイブルパラメータ $S_{\mathrm{o}}$, $m_{\mathrm{s}}$ を用いて, 2 母数ワイブル分布から $F$ が $5 \%, 10 \%$ (ガラス) および $30 \%, 40 \%\left(\mathrm{Al}_{2} \mathrm{O}_{3}\right)$ で計算される值とした. また, これら $\bar{\sigma}$ での静疲労寿命のワイブルパラメータ $t_{\mathrm{o}}, m_{\mathrm{f}}$ を表 1 に示寸. なお, 静荷重の負荷中に破断した場合は, 破断寿 命データとして取り扱った. 静荷重を負荷した後, クロスヘッド速度（Cross head speed；CHS） $0.05 \mathrm{~mm} / \mathrm{min}$ で 4 点曲げ残 存強度試験を行った. 残存強度 $\sigma_{\mathrm{R}}$ は $3 P_{\mathrm{R}}\left(L_{1}-L_{2}\right) / 2 w t^{2}$ として評価した. ここで, $P_{\mathrm{R}}$ は破壊荷重である.

\section{4. モデルの検証と残存強度特性}


図 1 にガラスの $\sigma_{\mathrm{R}}-t_{\mathrm{R}}$ プロットと式(6)から予測した様々な $F$ に対する曲線を示寸. また $n$ 值は, 文献 8 より 19.1 とした. ここで $n$ 值は, CHS を変化させた 4 点曲げ試験から $\sigma_{\max } \propto t_{\mathrm{eff}}^{-1 / n}$ ( $\sigma_{\mathrm{max}}$ は破壊強度, $t_{\mathrm{eff}}$ は有効負荷時間) の関係を用 いて評価している. ガラスの $\sigma_{\mathrm{R}}$ は, $\bar{\sigma}$ によらず $t_{\mathrm{R}}$ の増加に伴って減少しており，ばらつきの範囲内で予測值とよく一致して いる.したがって, ガラスに対しては本モデルの妥当性が確認できた.

図 2 に $\mathrm{Al}_{2} \mathrm{O}_{3}$ の $\sigma_{\mathrm{R}}-t_{\mathrm{R}}$ プロットと予測曲線を示寸.ここで $n$ 值は, ガラスと同様に評価した值であり，文献 8 より 24 とし

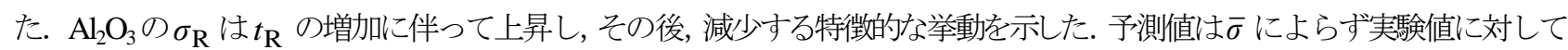
いずれも過小評価しており，予測值がほとんじ変化しない領域 $\left(t_{\mathrm{R}}=10^{0} \sim 10^{3} \mathrm{~s}\right)$ において顕著な $\sigma_{\mathrm{R}}$ の上昇が見られた. また予測值が低下寸る領域 $\left(t_{\mathrm{R}}=2 \times 10^{3} \sim 10^{4} \mathrm{~s}\right)$ において $\sigma_{\mathrm{R}}$ の低下が見られ, 図 $2(\mathrm{~b})$ に示すように予測值と一致する実験 值も存在するが, 本モデルでは $\mathrm{Al}_{2} \mathrm{O}_{3}$ の $\sigma_{\mathrm{R}}$ は十分に予測できない.

図 3 にガラスと $\mathrm{Al}_{2} \mathrm{O}_{3}$ の 4 点曲げ試験後の破面をそれぞれ示寸.ガラスでは，ミラー，ミスト，ハックルと呼 ばれる特徵的なぜい性破面様相が観察された。ゆえに潜在欠陥（グリフィスフロー）を起点とした SCG 破壊であ

Table 1 Weibull parameters of 4-point bending strength at CHS of $0.05 \mathrm{~mm} / \mathrm{min}$ and rupture life.

\begin{tabular}{|c|c|c|c|c|c|}
\hline \multirow[b]{2}{*}{ Materials } & \multicolumn{2}{|c|}{ Weibull parameters of 4-point bending strength } & \multicolumn{3}{|c|}{ Weibull parameters of rupture life } \\
\hline & $\begin{array}{c}\text { Scale parameter } \\
S_{\mathrm{o}}[\mathrm{MPa}]\end{array}$ & $\begin{array}{l}\text { Shape parameter } \\
m_{\mathrm{s}}\end{array}$ & $\begin{array}{c}\text { Applied stress } \\
\bar{\sigma}[\mathrm{MPa}]\end{array}$ & $\begin{array}{c}\text { Scale parameter } \\
t_{\mathrm{o}}[\mathrm{s}]\end{array}$ & $\begin{array}{l}\text { Shape parameter } \\
\qquad m_{\mathrm{f}}\end{array}$ \\
\hline \multirow{2}{*}{ Soda glass } & \multirow{2}{*}{89} & \multirow{2}{*}{6.1} & 54.8 & 4040.9 & 0.61 \\
\hline & & & 61.6 & 702.2 & 0.53 \\
\hline \multirow{2}{*}{$\mathrm{Al}_{2} \mathrm{O}_{3}$} & \multirow{2}{*}{331.2} & \multirow{2}{*}{19.2} & 313.9 & 1426.3 & 0.70 \\
\hline & & & 319.8 & 1149.9 & 0.77 \\
\hline
\end{tabular}
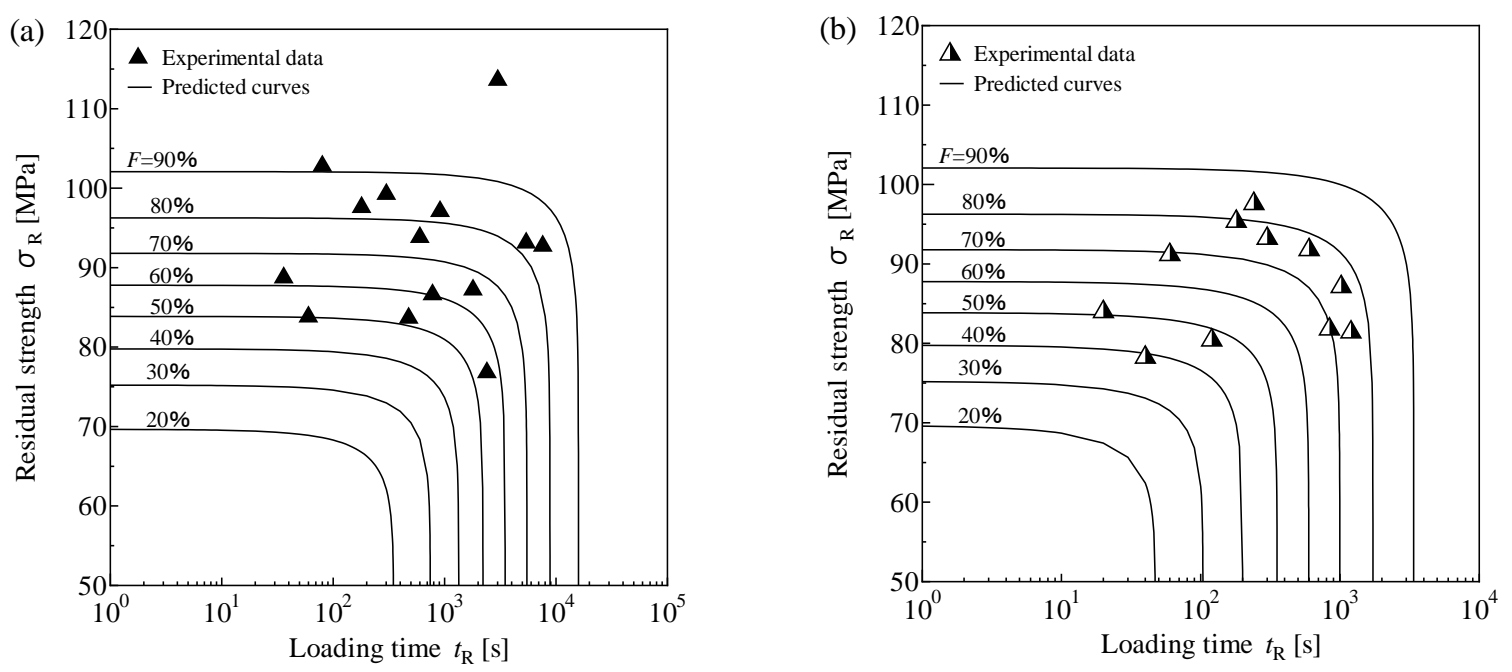

Fig.1 Measured and predicted residual strengths in soda glass subjected to constant stresses of (a) 54.8MPa and (b) 61.6MPa.
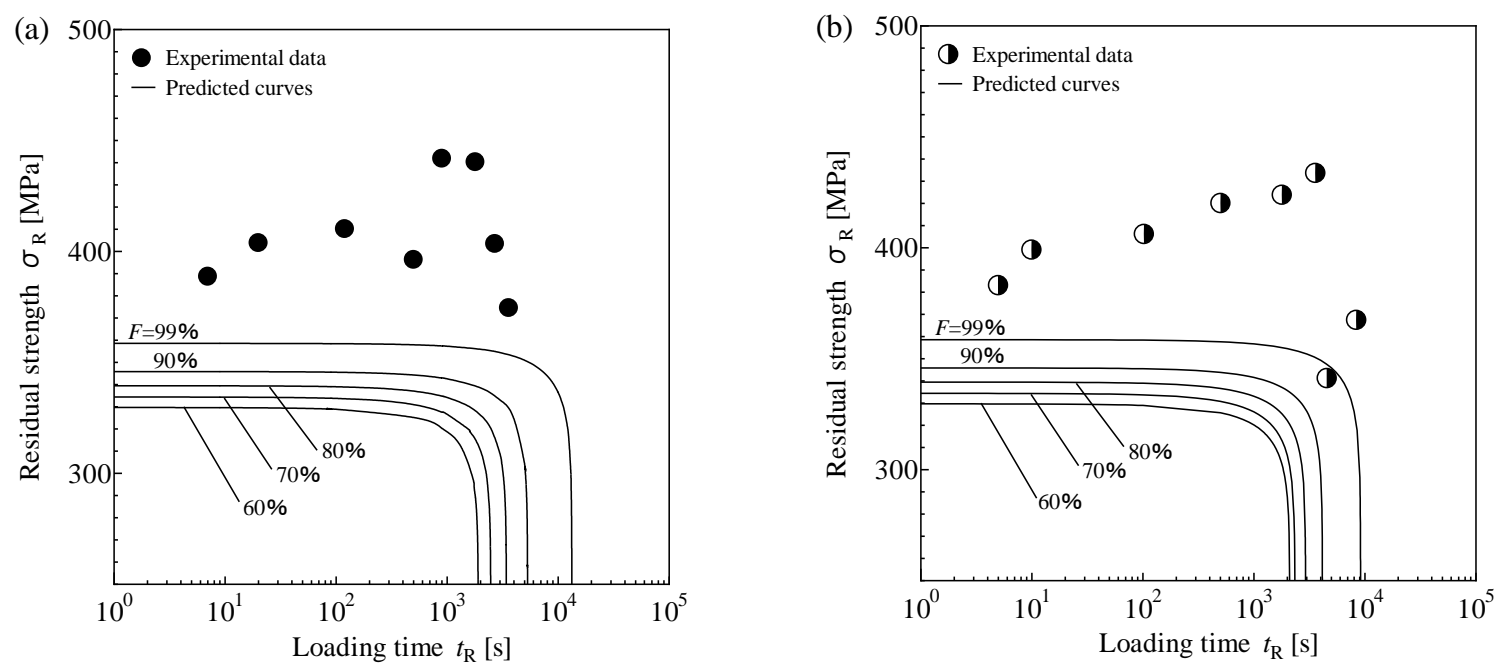

Fig.2 Measured and predicted residual strengths in $\mathrm{Al}_{2} \mathrm{O}_{3}$ subjected to constant stresses of (a) $313.8 \mathrm{MPa}$ and (b) $319.8 \mathrm{MPa}$. 
(a)

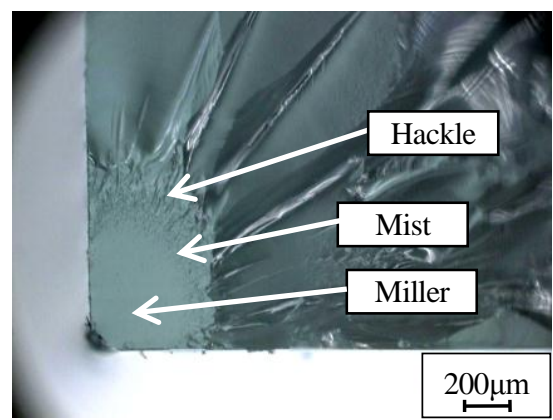

(b)

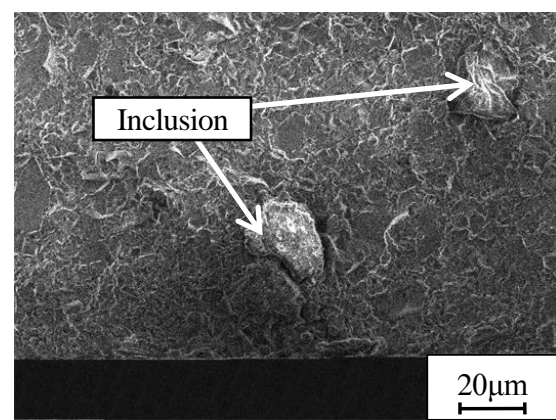

Fig.3 Fracture surfaces of (a) soda glass and (b) $\mathrm{Al}_{2} \mathrm{O}_{3}$ after 4-point bending test at CHS of $0.05 \mathrm{~mm} / \mathrm{min}$.

(a)

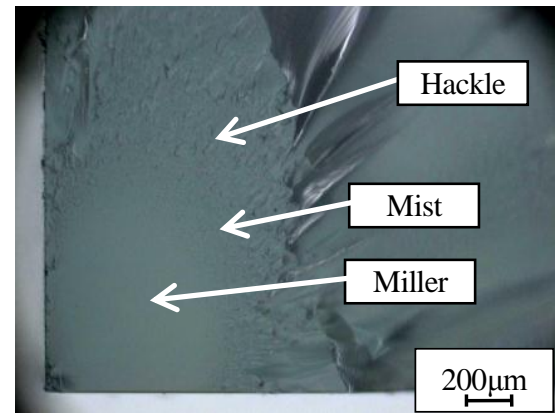

(b)

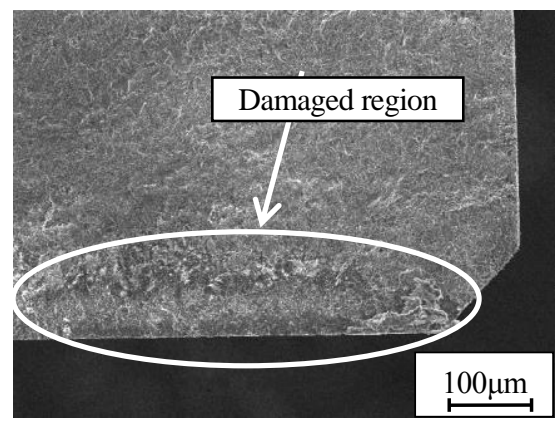

Fig. 4 Fracture surfaces of (a) soda glass $\left(\sigma_{\mathrm{R}}=91 \mathrm{MPa}, t_{\mathrm{R}}=5400 \mathrm{~s}, \bar{\sigma}=54.8 \mathrm{MPa}\right)$ and (b) $\mathrm{Al}_{2} \mathrm{O}_{3}\left(\sigma_{\mathrm{R}}=441 \mathrm{MPa}\right.$, $\left.t_{\mathrm{R}}=900 \mathrm{~s}, \quad \bar{\sigma}=313.9 \mathrm{MPa}\right)$ after residual strength test.

る.一方, $\mathrm{Al}_{2} \mathrm{O}_{3}$ の破面にはそのような特徵的な様相は見られず, 複数の介在物が観察された。 したがって, 介 在物が起点となり破壊したと考えられる. 図 4 に残存強度試験後のガラスと $\mathrm{Al}_{2} \mathrm{O}_{3}$ の破面をそれぞれ示寸.ガラ スの場合, 図 3 （a）と同様のぜい性破面様相が観察され，ミラー領域は図 3 （a）に比べて大きい。これは，静荷 重による SCG の拡大が原因と考えられる.ゆえにガラスの残存強度は SCG 機構に支配される. 一方 $\mathrm{Al}_{2} \mathrm{O}_{3}$ は, 図 3 （b）の破面とは大きく異なっており，引張側には広範囲に渡って激しい損傷が観察された．損傷領域の大き さは介在物よりもはるかに大きい，そのため $\mathrm{Al}_{2} \mathrm{O}_{3}$ の残存強度は，本モデルとは異なる機構に支配されると考え られる.

$\mathrm{Al}_{2} \mathrm{O}_{3}$ の特徵的な残存強度特性の原因の一つとして, $\mathrm{R}$ 曲線挙動の影響が予想される. $\mathrm{R}$ 曲線は, 長い予き裂か らのき裂進展に対して, き裂面の粒子架橋によってき裂進展抵抗值が上昇する挙動である。一般的に $\mathrm{Al}_{2} \mathrm{O}_{3}$ の長 い予き裂に対しては R 曲線挙動が認められている(9). しかしながら本実験は, 図 3 (b) に示寸ような多数の短い 介在物が存在する平滑試験片を用いて実施した。また図4（b）に示したように特徵的な様相を呈しており，き裂 進展椂相は観察されていない. ゆえに $\mathrm{R}$ 曲線挙動の影響は考えにくい. 一方, 上野ら ${ }^{(10)}$ は $\mathrm{Si}_{3} \mathrm{~N}_{4}$ の疲労寿命シミ ユレーションを行い, $n$ 值の大きなセラミックスの疲労寿命（き裂発生寿命とき裂進展寿命の和）は，負荷応力 の低下とともにき裂進展寿命よりもき裂発生寿命の占める割合が増加すると示している. すなわち, 長期の疲労 寿命を論じる上で，き裂進展以前の微視的な損傷の蓄積によってき裂に成長する過程（き裂発生過程）が重要な 役割を担うことを意味している。したがって破面観察の結果をふまえると, 図 5 に示寸模式図のような破壊メカ ニズムが推察される. 初めに, 静荷重によって引張応力が作用する表面近傍に介在物周りや粒界に存在する微視 的なガラス相の損傷がランダムに発生し, 損傷領域が形成される（図 5（a））。静荷重を除荷した後, 準静的荷 重負荷とともに損傷領域内においてさらに微視き裂が増加し，微視き裂同士が結合を始める．そして，複数の微 視き裂の集合体（クラスターき裂）が形成され（図 5 （b）），クラスターき裂まわりにおける応力拡大係数 $K$ が 臨界值 $K_{\mathrm{C}}$ に達すると, クラスターき裂を起点として破壊が起こる（図 5 (c) ）。したがって, 複数のクラスタ 一形成によって損傷許容性が創出することで見かけ上 $K_{\mathrm{C}}$ が上昇し, 残存強度は上昇する. そのため, 静荷重負 荷時間の増加に伴って損傷領域が拡大し, クラスター形成による損傷許容性が大きく創出するため, 残存強度は 静荷重負荷時間の増加に伴って増加したと推察される. 寸なわち, 静荷重下でのき裂発生過程中の微視的な損傷 の蓄積が残存強度を律速するため, $\mathrm{Al}_{2} \mathrm{O}_{3}$ に対して本モデルは適用できない. この結果は, セラミックスの強度 や寿命は，き裂発生過程が重要な役割を担うことを実験的に示している. 


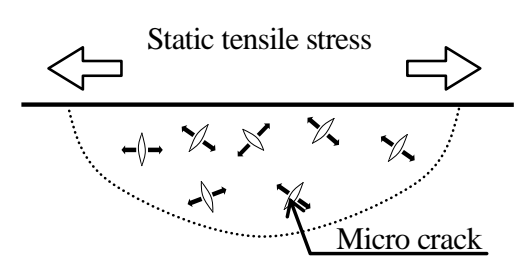

(a) Damage region is formed due to micro crack generation under static tensile stress.

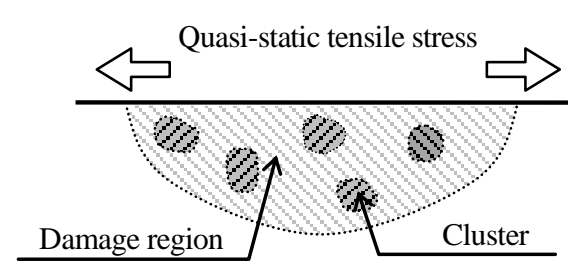

(b) Clusters are formed by uniting of micro cracks generated in the damage region.

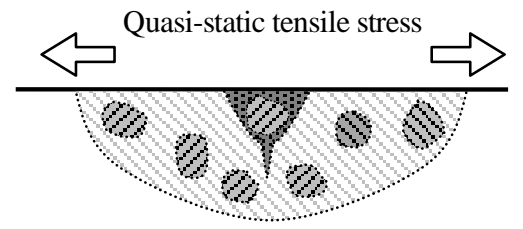

(c) Fracture occurs when stress intensity factor $K$ around a cluster reaches critical value $K_{\mathrm{C}}$.

Fig.5 Fracture mechanism of $\mathrm{Al}_{2} \mathrm{O}_{3}$ after static loading.

\section{5. 結言}

本研究では, SCG 理論に基づき静荷重を受けたセラミックスの残存強度予測モデルを構築し，ガラスおよ び $\mathrm{Al}_{2} \mathrm{O}_{3}$ の実験值と予測值を比較した. その結果, ガラスは予測值とよく一致した。一方, $\mathrm{Al}_{2} \mathrm{O}_{3}$ は予測值と 一致せず，負荷時間の増大とともに残存強度は上昇した。これは，静荷重下でのき裂発生過程中の微視的な損 傷の蓄積が残存強度を律速するためと考えられる。

\section{謝辞}

本研究は, 豊橋技術科学大学高専連携教育研究プロジェクト支援 $\mathrm{A}$ (共同研究者; 教授 戸田裕之 氏, 准教授 小林正和 氏) の助成および伊藤康治 君（現・豊橋技術科学大学）の協力を受けた. ここに記して感謝の意を表す.

\section{文献}

（1）宮崎広行，大司達樹，吉澤友一，“転がり軸受球用窒化ケイ素の圧子圧入(IF)法による破壊勒性測定法の国際規 格化（特集 窒化ケイ素系材料：過去から未来へ)”，セラミックス，Vol.47, (1) (2012), pp.42-45.

（2）伊藤義康，須山章子，“高強度反応焼結炭化ケイ素の微構造評価”, 材料, Vol.57, No.3 (2008), pp.304-309.

(3) Evans, A.G. and Fuller, E.R., "Crack propagation in ceramic materials under cyclic loading conditions", Metallurgical and Materials Transactions-B, Vol.5, No.1 (1974), pp.27-33.

(4) Evans, A.G. and Wiederhorn, S.M., "Proof testing of ceramic materials -an analytical basis for failure prediction", International Journal of fracture, Vol.10, No.3 (1974), pp.379-392.

(5) Ritter, J.E. and Humenik, J.N., "Static and dynamic fatigue of polycrystalline alumina", Journal of Materials Science, Vol.14, No.3 (1979), pp.626-632.

(6) Okabe, N. and Ikeda, T., "Strength evaluation method and design optimization for ceramic gas turbine blades", Materials science and engineering:A, Vol.143, Issues 1-2 (1991), pp.11-19.

(7) 野島武敏, “セラミックスの保証試験後の残留強度と破壊強度のワイブル分布の解析”, 日本機械学会論文集 A 編, Vol.64, No.627 (1998), pp.2832-2837.

(8) Matsuda, S. and Watanabe, R., "Estimation of Dynamic Fatigue Strengths in Brittle Materials under a Wide Range of Stress Rates", Journal of materials science, Vol.46, No.15 (2011), pp.5056-5063.

（9）鈴木賢治，田中啓介，坂井田喜久，山岸裕之，“圧こん予き裂からのき裂進展によるアルミナの R 曲線挙動”，材 料, Vol.44, No.504 (1995), pp.1133-1137.

(10) 上野明, 松野邦弥, “欠陥寸法の確率分布と微視き裂進展挙動を考慮した常圧焼結窒化ケイ素の疲労寿命シミュレ ーション”，材料, Vol.56, No.4 (2007), pp.357-363. 